\title{
The Synergy of Tradition and Innovation Leading to Sustainable Geographical Indication Products: A Literature Review
}

\author{
Alessandro Gocci ${ }^{1,2} \&$ Christoph Luetge ${ }^{2}$ \\ ${ }^{1}$ Max Planck Institute for Innovation and Competition, Munich, Germany \\ 2 TUM School of Management, Technical University of Munich, Munich, Germany \\ Correspondence: Alessandro Gocci, Max Planck Institute for Innovation and Competition, Marstallplatz 1, 80539 \\ Munich, Germany. E-mail: alessandro.gocci@ip.mpg.de
}

Received: April 4, $2020 \quad$ Accepted: May 3, $2020 \quad$ Online Published: May 9, 2020

doi:10.5539/jms.v10n1p152 URL: https://doi.org/10.5539/jms.v10n1p152

\begin{abstract}
The traditional production of geographical indications (GIs) are struggling to react to external influences such as climate change, changing market conditions. There is a call for innovation within GI products without compromising traditional practices. In GI research, tradition and innovation are often debated because it is apparent that they exclude each other. However, there are findings that a combination of these two elements can have effects on sustainability. Through acknowledging the synergy, diversification strategies are commonly used; those have a remarkable effect on all dimensions of sustainability (social, economic, environmental). The aim of this paper is to show evidence from literature stating that the incorporated tradition of GI products can exist in synergy with innovation. The TISyn (tradition-innovation synergy) model is presented as starting point for future research on this matter. We conclude that focusing on innovation within the GI scheme is required for a changing focus on sustainable productions. However, examples show that without taking tradition into account, GI stakeholders obtain negative outcomes.
\end{abstract}

Keywords: geographical indications, tradition, innovation, sustainability, synergy

\section{Introduction}

Traditional practices of food production are lost by the industrialization of the food sector. In response to this reality, the European Union (EU) introduced the scheme of Geographical Indications (GIs). The main focus lays on protecting traditional production of foodstuffs to preserve regional knowledge, however, there is a call for more sustainability and innovation within the different industries. This paper analyzes GI related literature from different scientific backgrounds to show that innovative measures can be taken without compromising traditions as strategy for a sustainable pathway. The synergy must be explored to give relevance to the GI scheme which incorporates tradition itself.

EU Regulation No 1151/2012 of the European Parliament sets the ground rules for the GI scheme for agricultural products and foodstuffs. Their main scope is to support rural development through fair rewards for the producers, and fostering knowledge and innovation with direct effects on sustainability (European Commission, 2012). Functioning as an intellectual property, the GI scheme communicates features such as quality and reputation through labelling food and non-food products (Quiñones-Ruiz et al., 2016). Depending on the geographical origin and the products' linkage to it, three different labels are used: traditional speciality guaranteed (TSG), protected geographical indications (PGI), and protected designation of origin (PDO) (European Commission, 2012).

EU regulations are, in general, reinterpreted on a national level and adjusted to specific needs of the countries considering the shared values on EU level. This heterogeneity influences the scientific studies, especially cross-national research is limited. Former studies mainly focused on legal aspects or economic issues related to GIs. In recent years, a shift towards sustainability and rural development related topics can be perceived. These changes in research open up different discourses, which leads to a diversification of the understanding of GIs. Downes (2000) for example argues that the EU regulation goes beyond the typical intellectual property right function; since it helps maintaining traditional practices and a product's reputation (Downes, 2000). Belletti et al. (2017) show that GI products through their reputation of high-quality can trigger regional effects (e.g., touristic 
activities, benefits for the local environment and economy) and stimulate certain types of innovation. The authors claim that the GI scheme does not operate solely as a legal tool but gives direction to pursue sustainable pathways (Belletti et al., 2017).

As shown in the paragraph before, the role of tradition and innovation within a GI context is complex. The possible influence of innovation is currently debated and perceived as challenge for the GI scheme. However, the producers are pushed to react to the global challenges such as climate change, unpredictable market conditions, changing consumer expectations, changing regulations and the need of meeting sustainability standards. According to these developments, this research highlights how innovation in synergy with tradition can influence GI products to react to these challenges. In order to do this, the following research questions are raised here:

1) How is tradition perceived in the GI discourse?

2) What are the main drivers of innovation within GI?

3) How can tradition exist in synergy with innovation?

4) Can this possible synergy support rural areas on their sustainability pathway?

After a short introduction of the research method, empirical evidence from literature is presented. This is followed by an examination of the key themes tradition, innovation and sustainability. To better highlight the synergy between tradition and innovation a theoretical model (TISyn) is proposed. Future research implications are presented within the conclusion.

\section{Research Method}

In order to examine the research questions, a qualitative literature review is conducted. One goal of this, apart from answering the research questions, is to show the state of the art in GI literature and to show further implications based on the key findings. The main spectrum of topics in literature concerns the legal and economic aspects, followed by rural development and sustainability. Occasionally, the mention of innovation within GI literature can be observed.

As first collection method a key word search in the main scientific search engines (Scopus, Web of Science, Google Scholar) was conducted. The main topics with their keywords are presented in Table 1, also synonyms were used throughout the search. The result of this first collection phase is that GI literature concerning tradition, innovation and sustainability is scarce and through the standard keyword search not all relevant literature can be found.

Table 1. Topics and keywords for first stage literature collection

\begin{tabular}{lll}
\hline Topic & Keywords & \\
\hline Geographical Indication (GI) & GI label & Protected Designation of Origin \\
& GI framework & Protected Geographical Indication \\
& GI scheme & Origin \\
Tradition & Traditional practices & Traditional Knowledge \\
& Traditional Know-how & Terroir \\
& Established techniques & \\
Innovation & Improved techniques & Upgrade techniques \\
& Amendments & Types of Innovation \\
Sustainability & Rural development & Multifunctionality \\
& Sustainable development & \\
\hline
\end{tabular}

Since the amount of available literature in this context was unsatisfactory, a "backward snowballing" technique was used. The reference lists of the first set of articles are investigated to expand the amount of relevant literature. This process is repeated until all literature for answering the research questions are identified (Jalali \& Wohlin, 2012; Webster \& Watson, 2002). Alternative to this technique, the "forward snowballing" which focuses on citations can be used as well (Jalali \& Wohlin, 2012). This was however, not taken into account in this study, because we wanted to reduce possible biases from other authors.

Based on the literature, a theoretical model was created showing the relationship of tradition and innovation and their influence on sustainable dimensions. The model is combined from the qualitative content analysis from the articles and the empirical findings in GI literature. Before going into the discussion, some empirical evidence from the recent years is now presented. 


\section{Empirical Data from GI Research}

Research in GI is often conducted through the analysis of a specific product or market segment, mainly with case studies. For example, Cozzi et al. (2018) analyzed 31 case studies from different European, and non-European countries. Based on those, they propose an economic theoretical framework for assessing sustainability focusing on multiple criteria. The framework highlights a strong connection between GI products and its territory, and takes into account the synergy of local resources and communities to strengthen rural development. Indicators such as profitability, carbon footprint, employment and agritourism were included to show the three dimensions of sustainability (Cozzi et al., 2018).

A similar focus has the case study of the Sorana bean (PGI) by Belletti et al. (2017). The authors assessed how a small production system can contribute to rural development goals. Within the case study nine semi-structured interviews with local producers were combined with legal documents like the product specification (legal document presenting GI production guidelines). Through the GI label the producers were able to sell the Sorana bean on a higher price level and in the same moment strengthen the local identity also due to of diversification strategies (e.g., agritourism). Furthermore, the authors noticed that through less economic pressure the farmers were more likely to innovate parts of their production. In this case the GI scheme did not act solely as legal tool, but influenced the sustainability in rural areas (Belletti et al., 2017).

In 2015, Belletti et al. investigated the relationship of the legal protection of GI and the environment through a content analysis of 107 product specifications. The research shows that $80 \%$ of those state at least one rule for protecting the environment. Remarkable is that some of those rules implicitly contain hints of the synergy of tradition and innovation to foster sustainability (Belletti et al., 2015). Similar results can be found in a former case study by Coq-Huelva et al. (2012) which is not investigating GI products but the relationship of innovation with the environment. The case study researches the Spanish olive oil production and how it overcomes environmental and territorial problems through innovation. The combination of the industrialized production with traditional local practices had a great effect on the sustainability (e.g., less soil erosion and improved water quality) (Coq-Huelva et al., 2012).

In contradiction to all those positive findings, Bowen and Zapata (2009) investigated the Mexican GI tequila and found negative outcomes on sustainability due to the registration as GI. In their case study, 27 small farmers in the area of Amatitan were involved through semi-structured interviews and workshops. The key findings show that local producers did not benefit from the GI label since the industry heavily modified the product specification. This led to an excessive standardization and harmed rural areas from an economic, social and environmental perspective. Based on the findings the researchers recommended a turn-around to more local and authentic practices which are related to the territory (terroir). This negative example of the introduction of the GI scheme shows that tradition and innovation require to be in synergy to obtain sustainable performances (Bowen \& Zapata, 2009).

The probably largest research was conducted by Larson in 2007. In a comprehensive study he investigated eleven case studies done by other GI researchers to provide an overview of global current trends. The main focus was on the conservation of biodiversity and rural developments and their influence on ending poverty, hunger alleviation and environmental justice. Larson identified the institution as key stakeholder in this context. Through their prominent role they influence the different forms of implementation of the GI label and therefore, have a direct influence on possible outcomes (Larson Guerra, 2007).

These empirical findings set the base for the discussion now on how tradition and innovation in synergy can influence sustainability in a GI context.

\section{The Synergy of Tradition and Innovation for Sustainability in GIs}

\subsection{Tradition}

Tradition is a key feature in the GI scheme, and it is part of various discourses. The basic rules are set by the EU Regulation No 1151/2012 on GI schemes, stating that only products with a history of production, usage and selling for at least thirty years can be identified as traditional (European Commission, 2012). Apart from the general EU perspective, tradition in GIs is perceived as a set of established practices which are meant to guarantee the transmission of knowledge among generations (Larson Guerra, 2004; Sautier et al., 2011). According to Addor and Grazioli (2002), this transmission supports the collectivity and upholds their culture. Furthermore, the reputation of GI products is grounded on traditional practices which influence the products characteristics. This represents the unique selling proposition of a GI product (Barjolle et al., 2011). Major strands in research connect the term tradition in the GI context with terroir and traditional knowledge and 
therefore, exemplary authors are presented in the following paragraphs.

In order to examine tradition in GIs the term terroir is recurrent. This French term focuses on the linkage of the product with its geographical area. Due to a lack of a precise definition authors focus on the multi-dimensionality of the term, connecting environmental, social and cultural aspects in interaction with the human factors and the geographical area (Riviezzo et al., 2017; Barjolle et al., 2011; Casabianca et al., 2005). For example, specific working skills are required to manufacture a product in an area with a certain microclimate, which has a direct impact on the products' features such as taste and quality (Barjolle et al., 2011; Delfosse, 1996; Belletti et al., 2011). One main aspect, according to Barjolle et al. (2011), is the preservation of collective know-how throughout generations. Established practices which are used in a restricted area of production in combination with the environment display the most common notion of terroir (Barjolle et al., 2011).

Similar to the discourses with terroir, traditional knowledge (TK) is associated with the GI scheme. There are diverse understandings of TK with no clear definition. According to Singhal (2008) TK includes "all intellectual activity in the industrial, scientific, literary, or artistic fields" (Singhal, 2008, p. 732). Furthermore, Singhal focuses on the dynamism of this term since cultures evolve over time and 'traditions' have to be preserved throughout this process. The author states that the GI scheme can support this through the protection against misuse of TK (Singhal, 2008). Downes (2000) highlights the importance of TK regarding biodiversity by stating that "[TK] informs resource management systems and practices of resource use in many indigenous and traditional farming cultures, thus helping to prevent the extensive loss of biodiversity and the decline in biological resources associated with industrial patterns of resource use" (Downes, 2000, p. 254). The communities are perceived as carriers of TK, and they can be strengthened through a better protection of it. Downes also criticizes the standardized industrial patterns which represent a harm to traditional practices and the environment (Downes, 2000). Both Downes and Singhal view GI as a possibility to protect TK. This is also supported by Sautier et al. (2011) who state that current trends show the potential of GIs as conservators and promoters of TK among local communities. GI therefore, goes beyond the protection against misuses, enabling other detectable effects (Sautier et al., 2011).

\subsection{Innovation}

The discussion of the existing literature on GIs moves from the variegated concept of tradition to the likewise challenging notion of innovation. Regulation (EU) No 1151/2012 and its previous regulations (510/2006, 2081/92) on GIs refer indirectly to innovation, through an amendment application which allows to change the product specification. This allows GI producers to react to different circumstances, such as changing regulations, climate change or market conditions, through upgrades of their knowledge (Quiñones Ruiz et al., 2018).

There are several attempts to define innovation in a way that it contains more than just technological improvements which are commonly associated with it (Avermaete et al., 2003). Lundvall suggests that "[Innovation is] an ongoing process of leaving, searching, and exploring which results in: (1) new products; (2) new techniques; (3) new forms of organization and (4) new markets" (Lundvall, 2010). Those types of innovation have been confirmed by Avermaete et al. (2003) through an empirical analysis of Belgium food sector firms (Avermaete et al., 2003). This typology is visualized in Figure 1, which offers some examples for the innovation and states that they are intertwined with. Hence, influencing and triggering each other. Nuvolari et al. (2014) identify innovation in agriculture through a similar interpretation: (1) biological innovations, in the form of new plant varieties or animal breeds, (2) improvements/adaptation of cultivation techniques, (3) mechanization and (4) use of fertilizers and pesticides (Nuvolari \& Tartari, 2014). This typology of innovation can be directly applied for analyzing GI products systematically. 


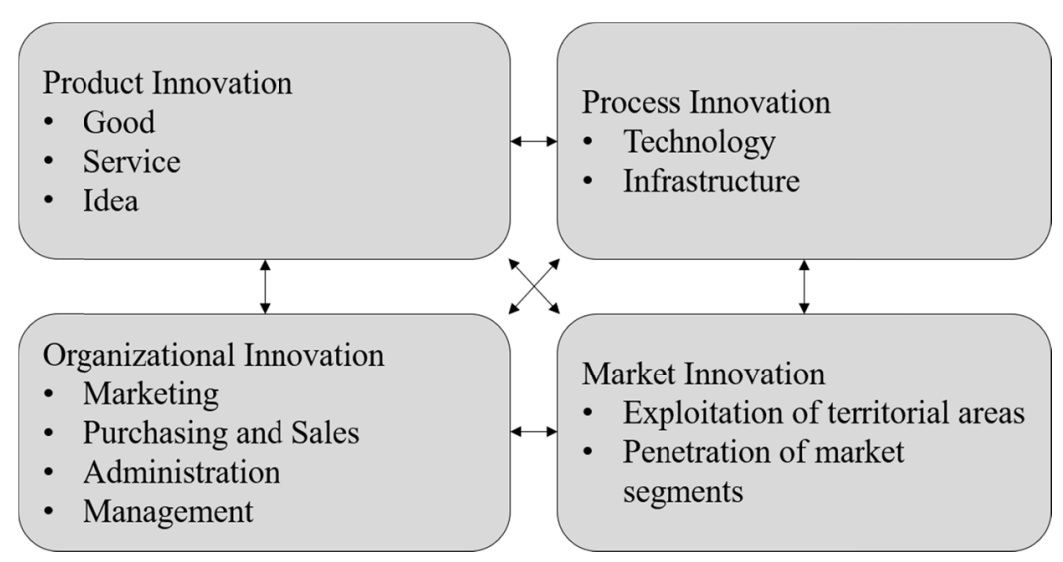

Figure 1. Map of innovation (Avermaete et al., 2003)

One might think that the product specification of GIs is a limitation for innovation in this context. However, Marty (1998) considers the codified rules within not as limiting but as a determining factor for the type of innovation (Marty, 1998). On the contrary, Kühne and Gellynck (2009) point out that innovation is not usually connected with traditional practices, since it could harm the identity of a local culture. In a subsequent paper Kühne et al. (2010) acknowledge the role of innovation for maintaining quality and transparency of a product (Kühne et al., 2010). Innovations do have effects on the whole production and can challenge companies. The product specification helps introducing useful inventions; hence, they can evolve into innovations (Mancini et al., 2019).

The linkage between tradition and innovation in GI research is acknowledged as challenging. Some authors agree that innovations play an important role for sustaining traditions and that it has a central role for addressing new market exigencies. According to Quiñones Ruiz et al. (2018), crises can stimulate innovation and therefore, encourage the renewal of traditional practices which might be outdated. Currently, the industrialized products are in crises due to changing consumer expectancies. The GI scheme can be recognized as answer to this, since GI producers follow a codified product specification (Quiñones Ruiz et al., 2018). From a historical perspective, Allaire et al. (2011) argue that the dynamic environment has always forced producers to engage in innovation, especially to overcome technical obstacles (Allaire et al., 2011). Larson (2007), to a further extent, evaluates innovation as key element for maintaining the quality of a product. Similar to Quiñones Ruiz et al. (2018), he perceives the GI system as a counter movement to the industrialization. Through the synergy of tradition and innovation consumer can expect a high quality and unique product (Larson Guerra, 2007). Mancini et al. (2019) perceive the territory as binding element of tradition and innovation. The territory includes all resources required for activating local communities to innovate their traditional consolidated practices (Mancini et al., 2019).

Larson (2007) regards the capacity of GI producers of combining innovation and tradition as an important advantage in the long-run (Larson Guerra, 2007). The role of innovation, however, raises the following question: "What triggers a GI producer to engage in innovative pathways without compromising their tradition?" Abrutyn et al. (2016) consider crises as the motor for shaping and directing innovation, especially the crises which have an impact on the environment, on population and culture (Abrutyn et al., 2016). More specifically in GI context, a GI producer makes efforts to react to the dynamic environment in form of new environmental conditions or technologies, new food safety standards and consumer purchasing habits (Quiñones Ruiz et al., 2018). Linnemann et al. (2006) identified the consumer as trigger for innovation within the GI scheme. The consumers' demands and preferences shape the production behavior which can influence the degree of innovation (Linnemann et al., 2006). The acceptance of an innovation depends on the cultural setting, e.g., influenced by nation state (Kühne et al., 2010), and also on the type of innovation and its influences on the product (Guerrero et al., 2009). Informing the consumer plays a key role for an invention to be successful. Marketing strategies can support the introduction of renewed practices, not only in a GI context (Giacomini et al., 2010).

From a network theory perspective Mancini et al. (2019) argue that innovation is closely related to the existing network in the geographical area (Mancini et al., 2019). They support their claim with Montanari and Sentieri, who argument that local cultures enable the relation between tradition and innovation (Montanari, 2004, 1993; Sentieri, 1993). One central aspect in network theory is, that not only human beings take part of the network, but resources and other elements are included into it. According to this thought, innovation is shaped by the interaction of the habitat. The network also encourages the circulation of information and enables knowledge 
exchange (Knickel et al., 2009). All presented triggers for innovation call for a meaningful governance system; otherwise inventions cannot evolve successfully (Belmin et al., 2018).

\subsection{Sustainability}

In recent years, the notion of sustainability has found increasing attention among different stakeholders. In science there is a lack of universal agreement on a single definition, even though attempts have been made along the years. In 1987, the United Nations for the first time introduced in the Brundtland Report the idea of sustainable development. SD is defined as following: "the development that meets the needs of the present without compromising the ability of future generations to meet their own needs" (United Nations, 1987). Since 1987, many other reports have been written and goals have been set. Currently, SD is supported through the sustainable development goals (SDG) which have been ratified on 25th September 2015 by the United Nations. With 17 different goals, economic growth should be fostered, while human lives are improved and the environment protected (United Nations, 2015). The goals nine, eleven, 13 and 15 point towards rural development, which is of great importance for most GI products, since it plays a key role for activating regional changes towards sustainability.

On an EU level, additionally to the SDGs, there is the Common Agriculture Policy (CAP), launched in 1962, in which rural development is defined as a tool for improving the quality of life and economic well-being of rural communities (OECD, 2006). From agri-food research Rota et al. (2013) call for an increase of sustainable practices to achieve common goals of sustainability (Rota et al., 2013). There are many different ways to achieve those, for example through rural development. On the one hand, Tregear et al. (2007) mention territorial capital as the key concept to foster rural development activities. Not only the production of regional foodstuffs, but also numerous activities like festivals, educational hiking tracks, and touristic initiatives are examples of how to use territorial capital (Tregear et al., 2007). On the other hand, the supply chain approach is challenged by Marsden et al. (2000), as they call for an evolution of traditional supply chains. New alternative chains or network approaches should lead to increased value of local products and strengthen their regional values and identity (Marsden et al., 2000). Similar to this, Ray (1998) uses the culture economy approach for explaining rural development. It describes the connection between economic relations of resources, production and consumption and the cultural aspects of a specific geographical area (Ray, 1998). According to Belletti et al. (2011) the definition of rural development, and its different key concepts, depend on the authors perception of rural cultures which influences the economic and non-economic understandings (Belletti et al., 2011).

Multifunctionality, in combination with rural development, is a key aspect of the relationship between GI producers and sustainability. With a holistic approach towards the production, other factors play a more important role than in conventional industries. In 2003, van der Ploeg and Roep state that multifunctionality is a fitting framework for approaching the new way of doing agriculture. This framework includes aspects like social linkages of the producer and consumer, and initiatives for strengthening the local culture and environment (van der Ploeg \& Roep, 2003). This argument can be supported by other authors who see multifunctionality as key concept for rural change, transition and development (van der Ploeg et al., 2000; Marsden et al., 2002). The traditional role of a farmer is influenced by this; instead of just producing their product, they now have to become rural entrepreneurs. They now engage in a mixed set of activities loading the product with cultural values (van der Ploeg \& Roep, 2003; van Huylenbroeck et al., 2007). Multifunctionality can be perceived as a tool for shifting from an economy of scale in rural areas to an economy of scope (Belletti et al., 2011; Brunori, 2003; Ventura \& Milone, 2005). This supports the main goals of rural development, focusing on social and environmental aspects through agro-tourism or sustainable farming (van der Ploeg \& Roep, 2003; Belletti et al., 2011). Multifunctionality is a legitimate concept for sustainable agriculture, however, it is unclear if the consumers reward the GI producers fairly for these efforts (Belletti et al., 2011). There is a call for economic research on this matter.

\section{Discussion and Implications}

The heterogeneity of the literature can be clearly observed in the review of different concepts of tradition, all of them having special foci. Terroir can be perceived as basic idea for GI productions, since it incorporates the natural and human factors. The passing on of skills can be considered as a preservation of GI tradition, even though small changes have to be made to adjust the production to different environmental conditions. These small innovations are a competitive advantage on the market. Also, TK and the identification with the product play a key role in GI, since they describe important aspects concerning the relation of the product and its producer. Both can be recognized as main drivers towards sustainability, since they focus on an economy of scope rather than scale. 
Connecting the presented empirical data and evidence from literature about tradition, innovation and sustainability within the GI scheme, the model about the synergy of tradition and innovation was contextualized. It is visualized in "Figure 2":

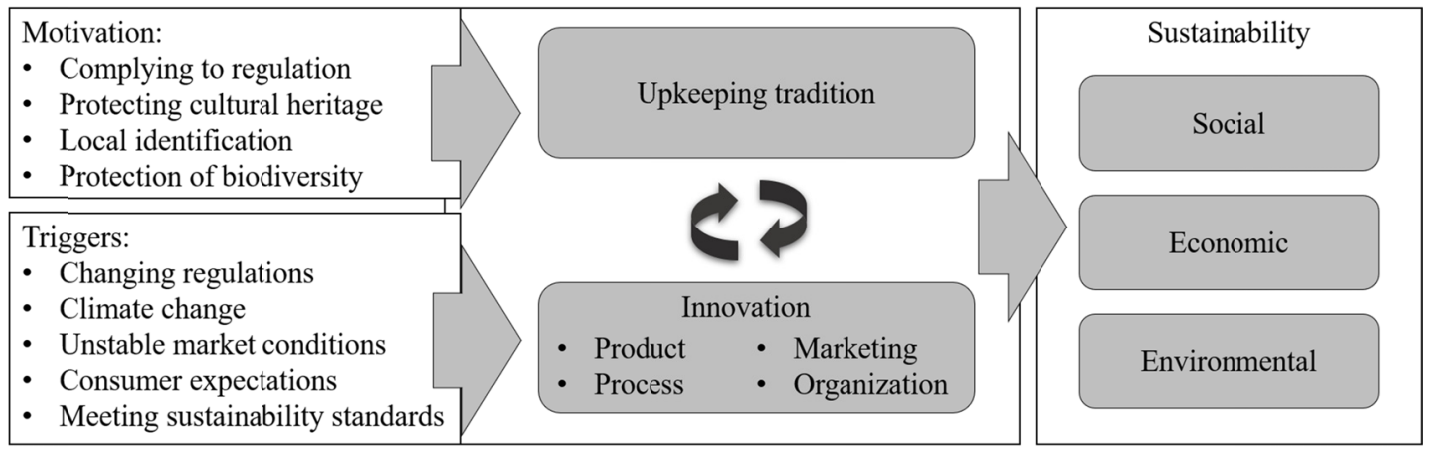

Figure 2. TISyn (tradition-innovation synergy) model

The name of the model is "TISyn", short for tradition-innovation synergy, and its goal is to visualize the different influences on this synergy and possible outcomes. The basic assumption is that a GI producer has fundamental motivations to maintain traditional practices in addition to complying to the EU Regulation No 1151/2012. In there, it states that a product can only be registered as GI if it has been produced and commercialized for at least 30 years (European Commission, 2012). The main motivation provided by the literature is the identification of local communities with traditional practices and with its product. There is a human need of sharing traditional knowledge as heritage from generation to generation (Addor \& Grazioli, 2002; Barjolle et al., 2011; Downes, 2000). Authors like Downes (2000) even recognize local practices as a supporting strategy for maintaining biodiversity within a geographical area (Downes, 2000).

Quiñones Ruiz et al. (2018) highlight that in order to maintain tradition a producer must engage in innovation as response to changing patterns (Quiñones Ruiz et al., 2018). The main triggers are shown in the model as main influence on the types of innovation, as they have been identified within literature. Connecting those findings with the empirical data presented, we argue that tradition and innovation can coexist. This possible synergy can lead to heterogenous effects, and possibly to a sustainable pathway. On one hand, Belletti et al. (2015) show in their case study that the combination of tradition and innovation activated a mindset of sustainable agriculture and therefore, lead to rural development (Belletti et al., 2015). On the other hand, Bowen and Zapata (2009) show in the case study of Mexican GI tequila that negative effects on the GI product happen if innovation does not respect traditional practices (Bowen \& Zapata, 2009). Stating clearly that a synergy of innovation and tradition is required to respect the production of GIs, also for maintaining quality and sustainability standards. Therefore, the TISyn model can help institutions and other stakeholders for the useful implementation of the GI scheme. Through the GI regulation trade-offs on environmental or social aspects can be prevented, thus setting the framework in which innovation happens.

From the sustainability discourse it can be observed that GI regulations comply with the key aspects, due to a focus on social, environmental and economic dimensions. In this paper the TISyn as a model, and the multifunctionality as theoretical approach have been found valid for analyzing the GIs sustainability. We recommend that GI producers acquire awareness about the synergy of tradition and innovation in order to keep their product competitive. The TISyn model can help researchers to analyze how GI producers overcome certain challenges. Through the combination of social factors with the GI production, an economic advantage compared to industrialized products might be observed.

The implementation of the GI framework differs from country to country, even though there are common shared values at the EU level. This influences the research required in the nation states, and the effects which can be measured. When constructing research in the GI field, the nation's history of registering GI products demands consideration. Based on the presented findings we recommend a broad investigation of European products and others related to the GI system, through a qualitative case study approach. The concepts presented here can be used as guiding principles for understanding each case and comparing them. The main focus should be on measuring sustainability in the specific areas and show positive and negative outcomes. The key concepts of 
innovation and tradition may support the investigations through creating a better understanding of the product environment. Moving away from a qualitative approach, some quantitative numbers stating that the production in the GI framework is profitable, not only for the producer but also for the community, should be included. Many aspects of the GI scheme are still unclear for research; there is a high demand for knowing how this legal framework can influence the sustainability of a country. This research can help the promotion of the GI scheme and therefore, support the preservation of local traditions.

\section{Acknowledgments}

\section{Disclosure of Potential Conflicts of Interest}

The authors declared no potential conflicts of interest with respect to the authorship and/or publication of this article.

\section{Research Involving Human Participants and/or Animals}

This chapter does not contain any studies with human participants or animals performed by any of the authors.

\section{Funding}

The authors received no financial support for the research and/or authorship of this article.

\section{References}

Abrutyn, S., van Ness, J., \& Taylor, M. A. (2016). Collective action and cultural change: Revisiting Eisenstadt's evolutionary theory. Journal of Classical Sociology, 16(4), 369-395. https://doi.org/10.1177/1468795X16656269

Addor, F., \& Grazioli, A. (2002). Geographical indications beyond wines and spirits: A roadmap for a better protection for geographical indications in the WTO/TRIPS agreement. J. World Intell. Prop., 5, 865. https://doi.org/10.1111/j.1747-1796.2002.tb00185.x

Allaire, G., Casabianca, F., ... Thevenod-Mottet, E. (2011). Geographical origin: A complex feature of agro-food products. Labels of Origin for Food: Local Development, Global Recognition, 1-12. https://doi.org/10.1079/9781845933524.0001

Avermaete, T., Viaene, J., Morgan, E. J., \& Crawford, N. (2003). Determinants of innovation in small food firms. European Journal of Innovation Management, 6(1), 8-17. https://doi.org/10.1108/14601060310459163

Barjolle, D., Sylvander, B., ... Thévenod-Mottet, E. (2011). Public policies and geographical indications. Labels of Origin for Food: Local Development, Global Recognition, 92-105. https://doi.org/10.1079/9781845933524.0092

Belletti, G., Marescotti, A., \& Brazzini, A. (2017). Old World Case Study: The Role of Protected Geographical Indications to Foster Rural Development Dynamics: The Case of Sorana Bean PGI. In W. van Caenegem \& J. Cleary (Eds.), The Importance of Place: Geographical Indications as a Tool for Local and Regional Development, Ius Gentium: Comparative Perspectives on Law and Justice (Vol. 58, pp. 253-276). Springer International Publishing, Cham. https://doi.org/10.1007/978-3-319-53073-4_10

Belletti, G., Marescotti, A. et al. (2011). Origin products, geographical indications and rural development. Labels of Origin for Food: Local Development, Global Recognition, 75-91. https://doi.org/10.1079/9781845933524.0075

Belletti, G., Marescotti, A., Sanz-Cañada, J., \& Vakoufaris, H. (2015). Linking protection of geographical indications to the environment: Evidence from the European Union olive-oil sector. Land Use Policy, 48, 94-106. https://doi.org/10.1016/j.landusepol.2015.05.003

Belmin, R., Casabianca, F., \& Meynard, J.-M. (2018). Contribution of transition theory to the study of geographical indications. Environmental Innovation and Societal Transitions, 27, 32-47. https://doi.org/10.1016/j.eist.2017.10.002

Bowen, S., \& Zapata, A. V. (2009). Geographical indications, terroir, and socioeconomic and ecological sustainability: The case of tequila. Journal of Rural Studies, 25(1), 108-119. https://doi.org/10.1016/j.jrurstud.2008.07.003

Brunori, G. (2003). Sistemi agricoli territoriali e competività.

Casabianca, F., Sylvander, B., Noël, Y., Béranger, C., Coulon, J.-B., \& Roncin, F. (2005). Terroir et Typicité: deux concepts-clés des Appellations d'Origine Contrôlée. Essai de définitions scientifiques et opérationnelles. 
Coq-Huelva, D., Sánchez-Escobar, F., ... Hervás-Fernández, I. (2012). Environmental and territorial problems of the Spanish olive oil sector and priorities for research and innovation: A Delphi analysis. In Local Agri-food Systems in a Global World: Market, Social and Environmental Challenges (Vol. 173, pp. 173-193). Cambridge Scholars Publishing in association with GSE Research.

Cozzi, E., Arfini, F., Donati, M., Guareschi, M., Mancini, M. C., Menozzi, D., \& Veneziani, M. (2018). The socio-economic sustainability of food quality schemes (FQSS): The case of Parmigiano Reggiano PDO. https://doi.org/10.20944/preprints201907.0053.v1

Delfosse, C. (1996). Qualité, liens au lieu et développement local. In F. Casabianca \& E. Valceschini (Eds.), $L a$ qualité dans l'agroalimentaire: émergence d'un champ de recherches (pp. 34-41). Paris, INRA.

Downes, D. R. (2000). How Intellectual Property Could Be a Tool to Protect Traditional Knowledge. Columbia Journal of Environmental Law, 25, 253-282.

European Commission. (2012). Regulation (EU) No 1151/2012 of the European Parliament and of the Council of 21 November 2012 on quality schemes for agricultural products and foodstuffs. Official Journal of the European Union, L343, 1-29.

Giacomini, C., Arfini, F., \& Roest, K. D. (2010). Interprofession and typical products: the case of Parmigiano Reggiano cheese.

Guerrero, L., Guàrdia, M. D., Xicola, J., Verbeke, W., Vanhonacker, F., Zakowska-Biemans, S., ... Hersleth, M. (2009). Consumer-driven definition of traditional food products and innovation in traditional foods. A qualitative cross-cultural study. Appetite, 52(2), 345-354. https://doi.org/10.1016/j.appet.2008.11.008

Jalali, S., \& Wohlin, C. (2012). Systematic literature studies: Database searches vs. backward snowballing. ACM, 29-38. https://doi.org/10.1145/2372251.2372257

Knickel, K., Brunori, G., Rand, S., \& Proost, J. (2009). Towards a Better Conceptual Framework for Innovation Processes in Agriculture and Rural Development: From Linear Models to Systemic Approaches. The Journal of Agricultural Education and Extension, 15(2), 131-146. https://doi.org/10.1080/13892240902909064

Kühne, B., \& Gellynck, X. (2009). Food Chain Networks as a Leverage for Innovation Capacity.

Kühne, B., Vanhonacker, F., Gellynck, X., \& Verbeke, W. (2010). Innovation in traditional food products in Europe: Do sector innovation activities match consumers' acceptance? Food Quality and Preference, 21(6), 629-638. https://doi.org/10.1016/j.foodqual.2010.03.013

Larson Guerra, J. (2004). Geographical indications and biodiversity: Bridges joining distant territories. Bridges, $8(2), 17-18$.

Larson Guerra, J. (2007). Relevance of geographical indications and designations of origin for the sustainable use of genetic resources (pp. 69-79). Rome (Italy): Global Facilitation Unit for Underutilized Species.

Linnemann, A. R., Benner, M., Verkerk, R., \& van Boekel, M. A. J. S. (2006). Consumer-driven food product development. Trends in Food Science \& Technology, 17(4), 184-190. https://doi.org/10.1016/j.tifs.2005.11.015

Lundvall, B.-A. (2010). National systems of innovation: Toward a theory of innovation and interactive learning (Vol. 2). Anthem press. https://doi.org/10.7135/UPO9781843318903

Mancini, M. C., Arfini, F., \& Guareschi, M. (2019). Innovation and typicality in localised agri-food systems: the case of PDO Parmigiano Reggiano. British Food Journal, 121(12), 3043-3061. https://doi.org/10.1108/BFJ-10-2018-0662

Marsden, T., Banks, J., \& Bristow, G. (2000). Food Supply Chain Approaches: Exploring their Role in Rural Development. Sociologia Ruralis, 40(4), 424-438. https://doi.org/10.1111/1467-9523.00158

Marsden, T., Banks, J., \& Bristow, G. (2002). The Social Management of Rural Nature: Understanding Agrarian-Based Rural Development. Environment and Planning A: Economy and Space, 34(5), 809-825. https://doi.org/10.1068/a3427

Marty, F. (1998). Which are the ways of innovation in PDO and PGI products? In F. Arfini \& C. Mora (Eds.), Typical and traditional products: rural effect and agro-industrial problems, Istituto di economia agraria e forestale. Facoltà di economia (pp. 41-58). Università di ....

Montanari, M. (1993). La fame e l'abbondanza: storia dell'alimentazione in Europa. Laterza. 
Montanari, M. (2004). Il cibo come cultura. Laterza, Roma - Bari.

Nuvolari, A., \& Tartari, V. (2014). Innovation, appropriability and productivity growth in agriculture: a broad historical viewpoint. Intellectual Property Rights: Legal and Economic Challenges for Development, 242. https://doi.org/10.1093/acprof:oso/9780199660759.003.0008

OECD. (Ed.) (2006). The new rural paradigm: Policies and governance. Organisation for Economic Co-operation and Development.

Quiñones Ruiz, X. F., Forster, H., Penker, M., Belletti, G., Marescotti, A., Scaramuzzi, S., ... Altenbuchner, C. (2018). How are food Geographical Indications evolving? - An analysis of EU GI amendments. British Food Journal, 120(8), 1876-1887. https://doi.org/10.1108/BFJ-02-2018-0087

Quiñones-Ruiz, X. F., Penker, M., Belletti, G., Marescotti, A., Scaramuzzi, S., Barzini, E., ... Samper-Gartner, L. F. (2016). Insights into the black box of collective efforts for the registration of Geographical Indications. Land Use Policy, 57, 103-116. https://doi.org/10.1016/j.landusepol.2016.05.021

Ray, C. (1998). Culture, Intellectual Property and Territorial Rural Development. Sociologia Ruralis, 38(1), 3-20. https://doi.org/10.1111/1467-9523.00060

Riviezzo, A., Garofano, A., Granata, J., \& Kakavand, S. (2017). Using terroir to exploit local identity and cultural heritage in marketing strategies: An exploratory study among Italian and French wine producers. Place Branding and Public Diplomacy, 13(2), 136-149. https://doi.org/10.1057/s41254-016-0036-4

Rota, C., Reynolds, N., \& Zanasi, C. (2013). Sustainable food supply chains: the role of collaboration and sustainable relationships. International Journal of Business and Social Science, 4(4).

Sautier, D., Biénabe, E., \& Cerdan, C. (2011). Geographical indications in developing countries. In E. Barham \& B. Sylvander (Eds.), Labels of origin for food: local development, global recognition (pp. 138-153). CABI, Wallingford. https://doi.org/10.1079/9781845933524.0138

Sentieri, M. (1993). Cibo e ambrosia. Storia dell'alimentazione mediterranea tra caso, necessità e Cultura Dedalo, Bari.

Singhal, S. (2008). Geographical indications and traditional knowledge. Journal of Intellectual Property Law \& Practice, 3(11), 732-738. https://doi.org/10.1093/jiplp/jpn160

Tregear, A., Arfini, F., Belletti, G., \& Marescotti, A. (2007). Regional foods and rural development: The role of product qualification. Journal of Rural Studies, 23(1), 12-22. https://doi.org/10.1016/j.jrurstud.2006.09.010

United Nations. (1987). Our common future: Brundtland Report. Report of the World Commission on Environment and Development.

United Nations. (2015). Transforming our World: The 2030 Agenda for Sustainable Development. A/RES/70/1.

van der Ploeg, J. D., Renting, H., Brunori, G., Knickel, K., Mannion, J., Marsden, T., ... Ventura, F. (2000). Rural Development: From Practices and Policies towards Theory. Sociologia Ruralis, 40(4), 391-408. https://doi.org/10.1111/1467-9523.00156

van der Ploeg, J. D., \& Roep, D. (2003). Multifunctionality and rural development: the actual situation in Europe. Multifunctional Agriculture: A New Paradigm for European Agriculture and Rural Development, 3, 37-54.

van Huylenbroeck, G., Vandermeulen, V., Mettepenningen, E., \& Verspecht, A. (2007). Multifunctionality of agriculture: a review of definitions, evidence and instruments. Living Reviews in Landscape Research, 1(3), 1-43. https://doi.org/10.12942/lrlr-2007-3

Ventura, F., \& Milone, P. (2005). Innovatività contadina e sviluppo rurale: un'analisi neo-istituzionale del cambiamento in agricoltura in tre regioni del Sud Italia (Vol. 7). FrancoAngeli.

Webster, J., \& Watson, R. T. (2002). Analyzing the past to prepare for the future: Writing a literature review. MIS Quarterly, 13-23.

\section{Copyrights}

Copyright for this article is retained by the author, with first publication rights granted to the journal.

This is an open-access article distributed under the terms and conditions of the Creative Commons Attribution license (http://creativecommons.org/licenses/by/4.0/). 